\title{
Design Intelligent Model base Online Tuning Methodology for Nonlinear System
}

\author{
Ali Roshanzamir, Farzin Piltan, Narges Gholami mozafari, Azita Yazdanpanah, Marjan Mirshekari \\ Research and Development Department, Institute of Advance Science and Technology-SSP, Shiraz/Iran, \\ http://WWW.IRANSSP.COM \\ Email: SSP.ROBOTIC@gmail.com
}

\begin{abstract}
In various dynamic parameters systems that need to be training on-line adaptive control methodology is used. In this paper fuzzy model-base adaptive methodology is used to tune the linear Proportional Integral Derivative (PID) controller. The main objectives in any systems are; stability, robust and reliability. However PID controller is used in many applications but it has many challenges to control of continuum robot. To solve these problems nonlinear adaptive methodology based on model base fuzzy logic is used. This research is used to reduce or eliminate the PID controller problems based on model reference fuzzy logic theory to control of flexible robot manipulator system and testing of the quality of process control in the simulation environment of MATLAB/SIMULINK Simulator.
\end{abstract}

Index Terms - PID Controller, Fuzzy logic methodology, Adaptive Techniques, Model reference fuzzy tuning.

\section{INTRODUCTION}

Continuum robots represent a class of robots that have a biologically inspired form characterized by flexible backbones and high degrees-of-freedom structures [1-3]. Theoretically, the compliant nature of a continuum robot provides infinite degrees of freedom to these devices. However, there is a limitation set by the practical inability to incorporate infinite actuators in the device. Most of these robots are consequently under actuated (in terms of numbers of independent actuators) with respect to their anticipated tasks. In other words they must achieve a wide range of configurations with relatively few control inputs. This is partly due to the desire to keep the body structures (which, unlike in conventional rigidlink manipulators or fingers, are required to directly contact the environment) "clean and soft", but also to exploit the extra control authority available due to the continuum contact conditions with a minimum number of actuators. For example, the Octarm VI continuum manipulator, discussed frequently in this paper, has nine independent actuated degrees-of-freedom with only three sections. Continuum manipulators differ fundamentally from rigid-link and hyper-redundant robots by having an unconventional structure that lacks links and joints. Hence, standard techniques like the Denavit-Hartenberg (D-H) algorithm cannot be directly applied for developing continuum arm kinematics. Moreover, the design of each continuum arm varies with respect to the flexible backbone present in the system, the positioning, type and number of actuators. The constraints imposed by these factors make the set of reachable configurations and nature of movements unique to every continuum robot. This makes it difficult to formulate generalized kinematic or dynamic models for continuum robot hardware. Thus, the kinematics (i.e. geometry based modeling) of a quite general set of prototypes of continuum manipulators has been developed and basic control strategies now exist based on these. The development of analytical models to analyze continuum arm dynamics (i.e. physics based models involving forces in addition to geometry) is an active, ongoing research topic in this field. From a practical perspective, the modeling approaches currently available in the literature prove to be very complicated and a dynamic model which could be conveniently implemented in an actual device's real-time controller has not been developed yet. The absence of a computationally tractable dynamic model for these robots also prevents the study of interaction of external forces and the impact of collisions on these continuum structures. This impedes the study and ultimate usage of continuum robots in various practical applications like grasping and manipulation, where impulsive dynamics [4-10] are important factors. Although continuum robotics is an interesting subclass of robotics with promising applications for the future, from the current state of the literature, this field is still in its stages of inception.

Controller (control system) is a device which can sense information from linear or nonlinear system (e.g., robot arm) to improve the systems performance and the immune system behavior [11-20]. In feedback control system considering that there are many disturbances and also variable dynamic parameters something that is really necessary is keeping plant variables close to the desired value. Feedback control system development is the most important thing in many different fields of safety engineering. The main targets in design control systems are safety stability, good disturbance rejection to reach the best safety, and small tracking error[21-33]. At present, in some applications robot arms are used in unknown and unstructured environment, therefore strong mathematical tools used in new control methodologies to design nonlinear robust controller with an acceptable safety performance (e.g., minimum error, good trajectory, disturbance rejection). According to the control theory, 
systems' controls are divided into two main groups: conventional control theory and soft computing control theory. Conventional control theories are work based on manipulator dynamic model. This technique is highly sensitive to the knowledge of all parameters of nonlinear robot manipulator's dynamic equation. Conventional control theory is divided into two main groups: linear control theory and nonlinear control theory. Soft computing (intelligent) control theory is free of some challenges associated to conventional control theory. This technique is worked based on intelligent control theory. This theory is divided into the following groups: fuzzy logic theory, neural network theory, genetic algorithm and neuro-fuzzy theory.

Although the fuzzy-logic control is not a new technique, its application in this current research is considered to be novel since it aimed for an automated dynamic-less response rather than for the traditional objective of uncertainties compensation[38-57]. The intelligent tracking control using the fuzzy-logic technique provides a cost-and-time efficient control implementation due to the automated dynamic-less input. This in turn would further inspire multi-uncertainties testing for continuum robot [58-69]. In project we can used fuzzy logic theory when a plant can be considered as a black box with outputs available for measurement and a possibility of changing inputs. The plant is supposed to be observable and controllable. Some information about the plant operation or plant control is available, which can or cannot be of a quantitative nature, but it can be formulated as a set of rules (maybe after some processing). An acceptable fuzzy control solution is possible, which should satisfy design specifications. It must not be optimal in regard to some criteria as it is hard to prove that a fuzzy control system is optimal and even stable. However, a fuzzy controller is able to provide a stable and 'good' solution.

This research has the following objectives:

- Design linear PID controller to control of continuum robot.

- Design fuzzy logic controller to tune the PID coefficients.

- Extract the nonlinear dynamic formulation to tune the fuzzy logic estimator.
This paper is organized as follows; section 2, is served as an introduction to the dynamic of continuum robot, design linear PID controller and fuzzy inference system. Part 3, introduces and describes the methodology algorithm. Section 4 presents the simulation results and discussion of this algorithm applied to a continuum robot and the final section describe the conclusion.

\section{THEORY}

Dynamic Formulation of Continuum Robot: The Continuum section analytical model developed here consists of three modules stacked together in series. In general, the model will be a more precise replication of the behavior of a continuum arm with a greater of modules included in series. However, we will show that three modules effectively represent the dynamic behavior of the hardware, so more complex models are not motivated. Thus, the constant curvature bend exhibited by the section is incorporated inherently within the model. The model resulting from the application of Lagrange's equations of motion obtained for this system can be represented in the form

$$
F_{\text {coeff }} \underline{\boldsymbol{\tau}}=\boldsymbol{D}(\underline{\boldsymbol{q}}) \underline{\ddot{q}}+\boldsymbol{C}(\underline{\boldsymbol{q}}) \underline{\dot{q}}+\boldsymbol{G}(\underline{\boldsymbol{q}})
$$

where $\tau$ is a vector of input forces and $\mathrm{q}$ is a vector of generalized co-ordinates. The force coefficient matrix $F_{\text {coeff }}$ transforms the input forces to the generalized forces and torques in the system. The inertia matrix, $D$ is composed of four block matrices. The block matrices that correspond to pure linear accelerations and pure angular accelerations in the system (on the top left and on the bottom right) are symmetric. The matrix $C$ contains coefficients of the first order derivatives of the generalized co-ordinates. Since the system is nonlinear, many elements of $C$ contain first order derivatives of the generalized co-ordinates. The remaining terms in the dynamic equations resulting from gravitational potential energies and spring energies are collected in the matrix $G$. The coefficient matrices of the dynamic equations are given below,

$$
\begin{aligned}
& \text { Fcoeff }= \\
& {\left[\begin{array}{cccccc}
1 & 1 & \cos \left(\theta_{1}\right) & \cos \left(\theta_{1}\right) & \cos \left(\theta_{1}+\theta_{2}\right) & \cos \left(\theta_{1}+\theta_{2}\right) \\
0 & 0 & 1 & 1 & \cos \left(\theta_{2}\right) & \cos \left(\theta_{2}\right) \\
0 & 0 & 0 & 0 & 1 & 1 \\
1 / 2 & -1 / 2 & 1 / 2 & -1 / 2 & 1 / 2+s_{2} \sin \left(\theta_{2}\right) & -1 / 2+s_{2} \sin \left(\theta_{2}\right) \\
0 & 0 & 1 / 2 & -1 / 2 & 1 / 2 & -1 / 2 \\
0 & 0 & 0 & 0 & 1 / 2 & -1 / 2
\end{array}\right]}
\end{aligned}
$$




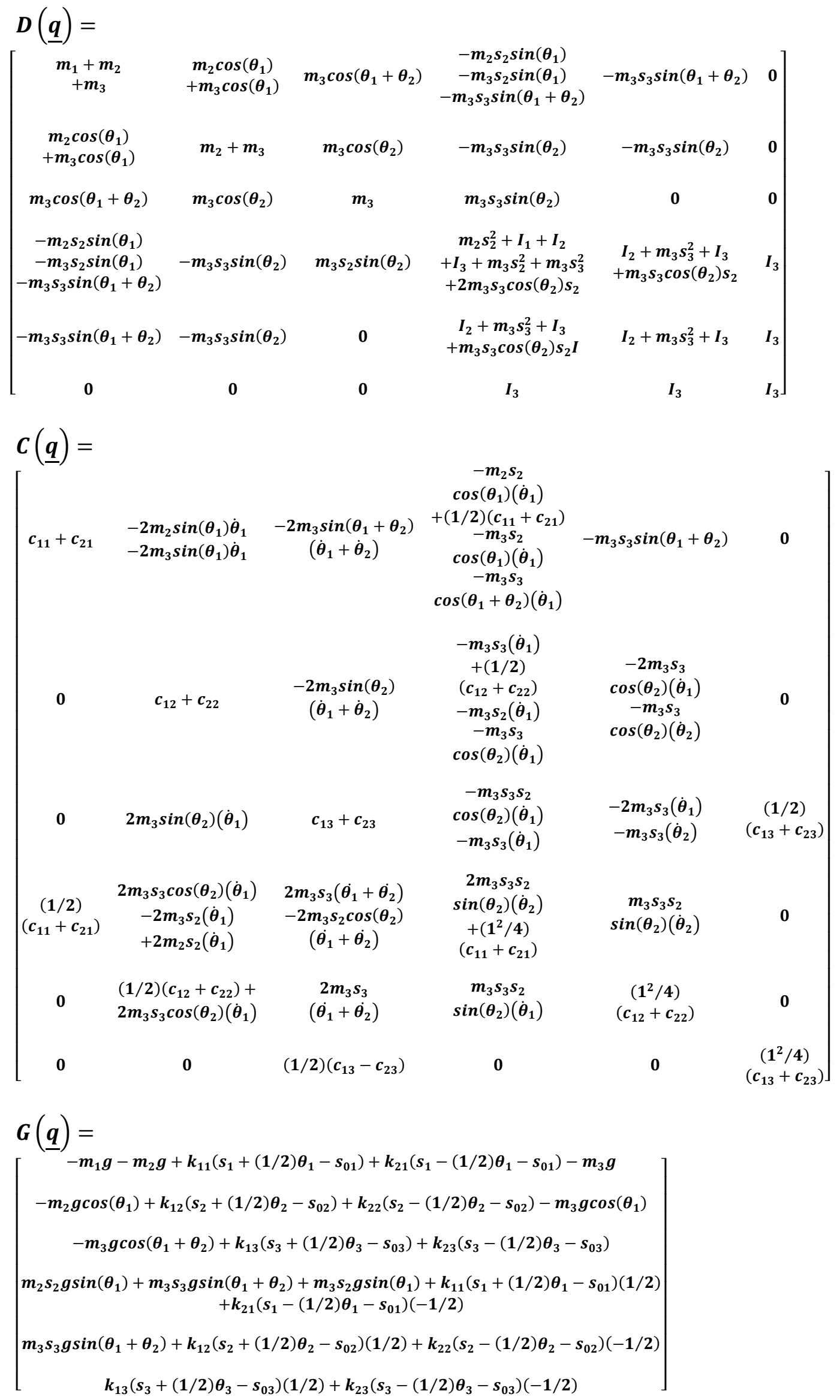


Fuzzy Logic Controller: Based on foundation of fuzzy logic methodology; fuzzy logic controller has played important rule to design nonlinear controller for nonlinear and uncertain systems [58-69]. However the application area for fuzzy control is really wide, the basic form for all command types of controllers consists of;

Input fuzzification (binary-to-fuzzy $[\mathrm{B} / \mathrm{F}]$ conversion) Fuzzy rule base (knowledge base), Inference engine and Output defuzzification (fuzzy-to-binary [F/B] conversion). Figure 1 shows fuzzy controller operation.

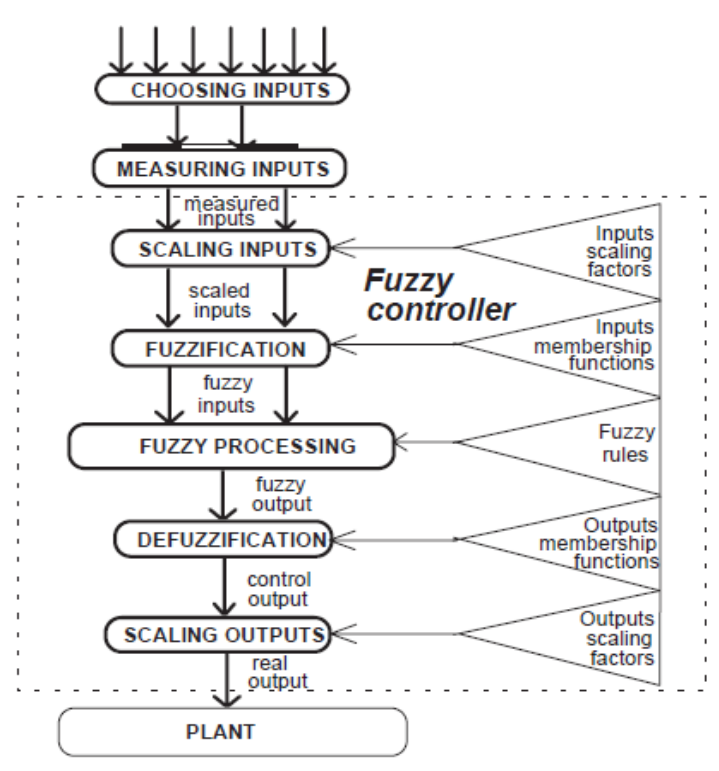

Fig 1: Fuzzy Controller operation

The fuzzy inference engine offers a mechanism for transferring the rule base in fuzzy set which it is divided into two most important methods, namely, Mamdani method and Sugeno method. Mamdani method is one of the common fuzzy inference systems and he designed one of the first fuzzy controllers to control of system engine. Mamdani's fuzzy inference system is divided into four major steps: fuzzification, rule evaluation, aggregation of the rule outputs and defuzzification. Michio Sugeno use a singleton as a membership function of the rule consequent part. The following definition shows the Mamdani and Sugeno fuzzy rule base

\section{if $x$ is $A$ and $y$ is $B$ then $z$ is $C$ 'mamdani' \\ if $x$ is $A$ and $y$ is $B$ then $z$ is $f(x, y)$ 'sugeno'}

When $x$ and $y$ have crisp values fuzzification calculates the membership degrees for antecedent part. Rule evaluation focuses on fuzzy operation $(A N D / O R)$ in the antecedent of the fuzzy rules. The aggregation is used to calculate the output fuzzy set and several methodologies can be used in fuzzy logic controller aggregation, namely, Max-Min aggregation, Sum-Min aggregation, Max-bounded product, Max-drastic product,
Max-bounded sum, Max-algebraic sum and Min-max. Two most common methods that used in fuzzy logic controllers are Max-min aggregation and Sum-min aggregation. Max-min aggregation defined as below;

$$
\begin{aligned}
& \mu_{U}\left(x_{k}, y_{k}, U\right)=\mu_{\cup \cup_{i=1}^{r} F R^{i}}\left(x_{k}, y_{k}, U\right) \\
& =\max \left\{\min _{i=1}^{r}\left[\mu_{R p q}\left(x_{k}, y_{k}\right), \mu_{p_{m}}(U)\right]\right\}
\end{aligned}
$$

The Sum-min aggregation defined as below

$$
\begin{aligned}
& \mu_{U}\left(x_{k}, y_{k}, U\right)=\mu_{\cup_{i=1}^{r} F R^{i}}\left(x_{k}, y_{k}, U\right) \\
= & \sum \min _{i=1}^{r}\left[\mu_{R} p q\right. \\
& \left.\left(x_{k}, y_{k}\right), \mu_{p_{m}}(U)\right]
\end{aligned}
$$

where $r$ is the number of fuzzy rules activated by $x_{k}$ and $y_{k}$ and also $\mu_{\cup_{i=1}^{r} F R^{i}}\left(x_{k}, y_{k}, U\right)$ is a fuzzy interpretation of $i-t h$ rule. Defuzzification is the last step in the fuzzy inference system which it is used to transform fuzzy set to crisp set. Consequently defuzzification's input is the aggregate output and the defuzzification's output is a crisp number. Centre of gravity method ( $C O G)$ and Centre of area method $(C O A)$ are two most common defuzzification methods, which $C O G$ method used the following equation to calculate the defuzzification

$$
\operatorname{COG}\left(x_{k}, y_{k}\right)=\frac{\sum_{i} U_{i} \sum_{j=1}^{r} \cdot \mu_{u}\left(x_{k}, y_{k}, U_{i}\right)}{\sum_{i} \sum_{j=1}^{r} \cdot \mu_{u}\left(x_{k}, y_{k}, U_{i}\right)}
$$

and $C O A$ method used the following equation to calculate the defuzzification

$$
\operatorname{COA}\left(x_{k}, y_{k}\right)=\frac{\sum_{i} U_{i} \cdot \mu_{u}\left(x_{k}, y_{k}, U_{i}\right)}{\sum_{i} \mu_{U} \cdot\left(x_{k}, y_{k}, U_{i}\right)}
$$

Where $\operatorname{COG}\left(\mathrm{x}_{\mathrm{k}}, \mathrm{y}_{\mathrm{k}}\right)$ and $\operatorname{COA}\left(\mathrm{x}_{\mathrm{k}}, \mathrm{y}_{\mathrm{k}}\right)$ illustrates the crisp value of defuzzification output, $U_{i} \in U$ is discrete element of an output of the fuzzy set, $\mu_{U} \cdot\left(x_{k}, y_{k}, U_{i}\right)$ is the fuzzy set membership function, and $r$ is the number of fuzzy rules.

Design PID Controller: Design of a linear methodology to control of continuum robot manipulator was very straight forward. Since there was an output from the torque model, this means that there would be two inputs into the PID controller. Similarly, the outputs of the controller result from the two control inputs of the torque signal. In a typical PID method, the controller corrects the error between the desired input value and the measured value. Since the actual position is the measured signal. Figure 2 shows linear PID methodology, applied to continuum robot manipulator [21-34].

$$
\begin{gathered}
e(t)=\theta_{a}(t)-\theta_{d}(t) \\
U_{P I D}=K_{p_{a}} e+K_{V_{a}} \dot{e}+K_{I} \sum e
\end{gathered}
$$




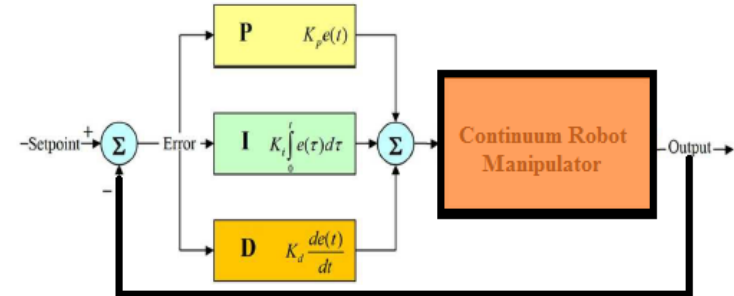

Fig 2: Block diagram of linear PID method

The model-free control strategy is based on the assumption that the joints of the manipulators are all independent and the system can be decoupled into a group of single-axis control systems [18-23]. Therefore, the kinematic control method always results in a group of individual controllers, each for an active joint of the manipulator. With the independent joint assumption, no a priori knowledge of robot manipulator dynamics is needed in the kinematic controller design, so the complex computation of its dynamics can be avoided and the controller design can be greatly simplified. This is suitable for real-time control applications when powerful processors, which can execute complex algorithms rapidly, are not accessible. However, since joints coupling is neglected, control performance degrades as operating speed increases and a manipulator controlled in this way is only appropriate for relatively slow motion $[44,46]$. The fast motion requirement results in even higher dynamic coupling between the various robot joints, which cannot be compensated for by a standard robot controller such as PID [50], and hence model-based control becomes the alternative.

\section{METHODOLOGY}

The main goal to design PID controller is tuning the coefficient. To off-line tuning Gradient Descent Optimization theory is introduced. Gradient Descent Optimization (GDO) is one of the evolutionary optimization algorithms in the branch of non intelligence [10-12]. This algorithm was inspired by the social movement behavior of the birds in the flock searching for food. Compared to the other evolutionary algorithms, the main excellences of this algorithm are: Simple concept, easy to implement, robustness in tuning parameters, minimum storage space and both global and local exploration capabilities. These birds in a flock are symbolically described as particles. These particles are supposed to a swarm "flying" through the problem space. Each particle has a position and a velocity. Any particle's position in the problem space has one solution for the problem. When a particle transfers from one place to another, a different problem solution is generated. Cost function evaluated the solution in order to provide the fitness value of a particle. "Best location" of each particle which has experienced up to now, is recorded in their memory, in order to determine the best fitness value. Particles of a gradient descent transmit the best location with each other to adapt their own location according to this best location to find the global minimum point. For every generation, the new location is computed by adding the particle's current velocity to its location. GDO is initialized with a random population of solutions in $\mathrm{N}$ dimensional problem space, the $\mathrm{i}$ th particle changes and updates its position and velocity according to the following formula:

$$
\begin{aligned}
& V_{i d}=w \times\left(V_{i d}+C_{1} \times \operatorname{rand}_{1} *\left(P_{i d}-\right.\right. \\
& \left.\left.X_{i d}\right)+C_{2} \times \operatorname{rand}_{2} \times\left(P_{g d}-X_{i d}\right)\right)
\end{aligned}
$$

Where $\boldsymbol{X}_{\boldsymbol{i d}}$ is calculated by

$$
X_{i d}=X_{i d}+V_{i d}
$$

Where $\boldsymbol{V}_{\boldsymbol{i d}}$ is the inertia weight implies the speed of the particle moving along the dimensions in a problem space. $\boldsymbol{C}_{1}$ and $\boldsymbol{C}_{2}$ are acceleration parameters, called the cognitive and social parameters; $\boldsymbol{r a n d}_{1}$ and rand $_{\mathbf{2}}$ are functions that create random values in the range of $(0,1)$. $\boldsymbol{X}_{\boldsymbol{i d}}$ is the particle's current location; $\boldsymbol{P}_{\boldsymbol{i d}}$ (personal best) is the location of the particle experienced its personal best fitness value; $\boldsymbol{P}_{\boldsymbol{g d}}$ (global best) is the location of the particle experienced the highest best fitness value in entire population; $\boldsymbol{d}$ is the number of dimensions of the problem space; $\boldsymbol{W}$ is the momentum part of the particle or constriction coefficient [5] and it is calculated based on the following equation;

$$
\begin{gathered}
W=2 /\left(2-\varphi-\sqrt{\varphi^{2}-4 \varphi}\right) \\
\varphi=C_{1}+C_{2} \quad, \quad \varphi>4
\end{gathered}
$$

Equation 10 needs each particle to record its location $\mathrm{X}_{\mathrm{id}}$, its velocity $\mathrm{V}_{\mathrm{id}}$, its personal best fitness value $\mathrm{P}$ id, and the whole population's best fitness value $\mathrm{P}_{\mathrm{gd}}$.

On the basis of following equation the best fitness value $\mathrm{Xi}$ is updated at each generation, where the sign $f($.$) represents the cost function; X_{i}($.$) indicated the best$ fitness values; and $t$ denotes the generation step.

$$
\begin{aligned}
& X_{i}(t+\mathbf{1})= \\
& \left\{\begin{array}{cl}
X_{i}(t) & f\left(P_{d}(t+1)\right) \leq X_{i}(t) \\
f\left(P_{d}(t+1)\right) & f\left(P_{d}(t+1)\right)>X_{i}(t)
\end{array}\right.
\end{aligned}
$$

In GDO, the knowledge of each particle will not be substituted until the particle meets a new position vector with a higher competence value than the currently recorded value in its memory [11-12]. External disturbances influence on tracking trajectory, error rate and torque which result in chattering. But the values are not such a great values and these oscillations are in all physical systems. So, the sliding mode controller can reject perturbations and external disturbances if these parameters adjust properly. So the methodology which is applied in this paper in order to select the best values for 
these deterministic coefficients to accomplish high performance control is the Gradient Descent Optimization algorithm. This algorithm tunes the gains and determines the appropriate values for these parameters in harmony with the system which was introduced in rear part.

The second part of this paper is focused on the extract the nonlinear term of continuum robot to sensitive tuning. Based on nonlinear formulation:

$$
\underline{U_{\text {nonlinear }}}=C(\underline{q}) \underline{\dot{q}}+G(\underline{q})
$$

The third part is fuzzy logic design; in this part 49 rule base PD fuzzy controller is design. Based on previous discussion, fuzzy logic controller is work based on nonlinear dynamic rule bases. However this controller work in many applications but it cannot guarantee reliability and stability.

The formulation of this controller is;

$$
\begin{gathered}
U_{P I D-f u z z y}=K_{p_{a}} U_{f u z z y}+K_{V_{a}} \dot{U}_{f u z z y} \\
+K_{I} \sum U_{f u z z y}
\end{gathered}
$$

Based on fuzzy logic methodology

$$
f(x)=U_{f u z z y}=\sum_{l=1}^{M} \theta^{T} \zeta(x)
$$

where $\theta^{T}$ is adjustable parameter (gain updating factor) and $\zeta(x)$ is defined by;

$$
\zeta(x)=\frac{\sum_{i} \mu\left(x_{i}\right) x_{i}}{\sum_{i} \mu\left(x_{i}\right)}
$$

Where $\mu\left(x_{i}\right)$ is membership function. According to the hybrid control theory;

$$
\begin{aligned}
& \tau=\left(U_{\text {fuzzy }} \times U_{P I D}\right)+U_{\text {nonlinear }} \\
&=U_{\text {nonlinear }} \\
&+\sum_{l=1}^{M} \theta^{T} \zeta(x) \\
& \times\left[K_{p_{a}} U_{\text {fuzzy }}\right. \\
&+K_{V_{a}} \dot{U}_{\text {fuzzy }} \\
&\left.+K_{I} \sum U_{\text {fuzzy }}\right]
\end{aligned}
$$

One of the main artificial intelligence techniques is fuzzy logic theory. In this theory the behavior and dynamic of controller is defined by rule base. However defined and number of rule base play important role to design high quality controller but system has limitation to the number of rule base to implementation and the speed of response. Design of error-based fuzzy based on Mamdani's fuzzy inference method has four steps, namely, fuzzification, fuzzy rule base and rule evaluation, aggregation of the rule output (fuzzy inference system) and defuzzification.
Fuzzification: the first step in fuzzification is determine inputs and outputs which, it has two inputs $(e, \dot{e})$ and one output $\left(\tau_{f u z z y}\right)$. The inputs are error (e) which measures the difference between desired and actual output position, and the change of error $(\dot{e})$ which measures the difference between desired and actual velocity and output is fuzzy equivalent torque. The second step is chosen an appropriate membership function for inputs and output which, to simplicity in implementation because it is a linear function with regard to acceptable performance triangular membership function is selected in this research. The third step is chosen the correct labels for each fuzzy set which, in this research namely as linguistic variable. Based on experience knowledge the linguistic variables for error (e) are; Negative Big (NB), Negative Medium (NM), Negative Small (NS), Zero (Z), Positive Small (PS), Positive Medium (PM), Positive Big (PB), and experience knowledge it is quantized into thirteen levels represented by: $-6,-5,-4,-3,-2,-1,0,1,2,3,4,5,6$ the linguistic variables for change of error $(\dot{e})$ are; Fast Left (FL), Medium Left (ML), Slow Left (SL),Zero (Z), Slow Right (SR), Medium Right (MR), Fast Right (FR), and it is quantized in to thirteen levels represented by: $-6,-5$, $0.4,-3,-2,-1,0,1,2,3,4,5,6$, and the linguistic variables to find the output are; Large Left (LL), Medium Left (ML), Small Left (SL), Zero (Z), Small Right (SR), Medium Right (MR), Large Right (LR) and it is quantized in to thirteen levels represented by: : $-6,-5,-4$, $-3,-2,-1,0,1,2,3,4,5,6$

Fuzzy rule base and rule evaluation: the first step in rule base and evaluation is to provide a least structured method to derive the fuzzy rule base which, expert experience and control engineering knowledge is used because this method is the least structure of the other one and the researcher derivation the fuzzy rule base from the knowledge of system operate and/or the classical controller. Design the rule base of fuzzy inference system can play important role to design the best performance of fuzzy sliding mode controller, that to calculate the fuzzy rule base the researcher is used to heuristic method which, it is based on the behavior of the control of robot manipulator. The complete rule base for this controller is shown in Table 1. Rule evaluation focuses on operation in the antecedent of the fuzzy rules in fuzzy sliding mode controller. This part is used $A N D / O R$ fuzzy operation in antecedent part which $A N D$ operation is used.

Table 1: Fuzzy Controller Rule Table

\begin{tabular}{|l|l|l|l|l|l|l|l|}
\hline$\dot{e} / \boldsymbol{e}$ & NB & NM & NS & ZE & PS & PM & PB \\
\hline NB & NB & NB & NB & NM & NS & NS & ZE \\
\hline NM & NB & NM & NM & NM & NS & ZE & PS \\
\hline NS & NB & NM & NS & NS & ZE & PS & PM \\
\hline ZE & NB & NM & NS & ZE & PS & PM & PB \\
\hline PS & NM & NS & ZE & PS & PS & PM & PB \\
\hline PM & NS & ZE & PS & PM & PM & PM & PB \\
\hline PB & ZE & PS & PS & PM & PB & PB & PB \\
\hline
\end{tabular}


Aggregation of the rule output (Fuzzy inference): Max-Min aggregation is used in this work.

Defuzzification: The last step to design fuzzy inference in our fuzzy sliding mode controller is defuzzification. This part is used to transform fuzzy set to crisp set, therefore the input for defuzzification is the aggregate output and the output of it is a crisp number. Center of gravity method $(C O G)$ is used in this research. The next step in this research is online tuning the fuzzy gain updating factors and PID coefficients based on PID controller.

\section{RESULTS AND DISCUSSION}

Proposed method was tested to Step response trajectory. In this simulation, to control position of continuum robot without and with external disturbance the simulation was implemented in MATLAB/SIMULINK environment. These systems are tested by band limited white noise with a predefined $40 \%$ of relative to the input signal amplitude. This type of noise is used to external disturbance in continuous and hybrid systems and applied to nonlinear dynamic of these controllers.

Tracking performances: Based on Fig 3, pure PID controller has a slight transient oscillation, to solve this challenge the output gain updating factor of fuzzy modelreference controller is applied to PID controller. In this design pure PID controller has about $5 \%$ overshoot but both of two controllers have the same rise time.

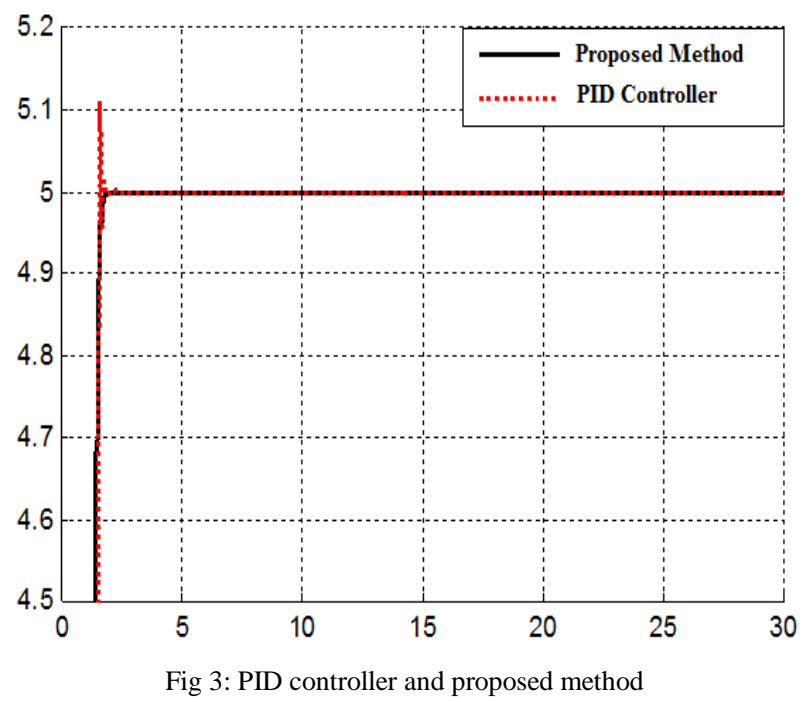

Disturbance rejection: Figure 4 shows the power disturbance elimination in proposed method and pure PID controller in presence of external disturbance and uncertainty parameters. The disturbance rejection is used to test and analyzed the robustness comparisons of these controllers for step trajectory. A band limited white noise with predefined of $40 \%$ the power of input signal value is applied to the step trajectory. According to the following graph, pure PID controller has moderate fluctuation in presence of external disturbance and uncertainty.

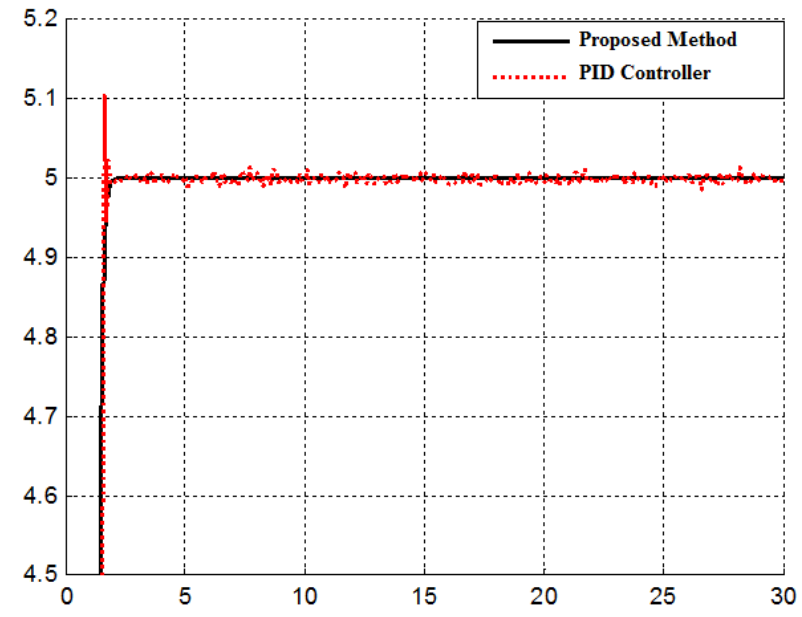

Fig 4: PID controller and proposed method in presence of external disturbance

Based on above graph, pure PID controller has many challenges in presence of external disturbance.

\section{CONCLUSION}

The central issues and challenges of non linear control and estimation problems are to satisfy the desired performance objectives in the presence of noises, disturbances, parameter perturbations, un-modeled dynamics, sensor failures, actuator failures and time delays. Evaluation algorithm proposed controller has shown growing popularity in both industry and academia. To improve the optimality and robustness, we have proposed adaptive model reference fuzzy estimator based on 49 rule base. Fuzzy logic controller is used to estimate highly nonlinear dynamic parameters. Mixed performance criteria have been used to design the controller and the relative weighting matrices of these criteria can be achieved by choosing different coefficient matrices. The simulation studies show that the proposed method provides a satisfactory alternative to the existing nonlinear control approaches.

\section{ACKNOWLEDGMENT}

The authors would like to thank the anonymous reviewers for their careful reading of this paper and for their helpful comments. This work was supported by the SSP Institute of Advance Science and Technology Program of Iran under grant no. 2013-Persian Gulf-2A.

\section{REFERENCES}

[1] T. R. Kurfess, Robotics and automation handbook: CRC, 2005.

[2] J. J. E. Slotine and W. Li, Applied nonlinear control vol. 461: Prentice hall Englewood Cliffs, NJ, 1991.

[3] L. Cheng, et al., "Multi-agent based adaptive consensus control for multiple manipulators with kinematic uncertainties," 2008, pp. 189-194.

[4] J. J. D'Azzo, et al., Linear control system analysis and design with MATLAB: CRC, 2003. 
[5] B. Siciliano and O. Khatib, Springer handbook of robotics: Springer-Verlag New York Inc, 2008.

[6] I. Boiko, et al., "Analysis of chattering in systems with second-order sliding modes," IEEE Transactions on Automatic Control, vol. 52, pp. 2085-2102, 2007.

[7] J. Wang, et al., "Indirect adaptive fuzzy sliding mode control: Part I: fuzzy switching," Fuzzy Sets and Systems, vol. 122, pp. 21-30, 2001.

[8] F. Piltan, et al., "Artificial Control of Nonlinear Second Order Systems Based on AFGSMC," Australian Journal of Basic and Applied Sciences, 5(6), pp. 509-522, 2011.

[9] V. Utkin, "Variable structure systems with sliding modes," Automatic Control, IEEE Transactions on, vol. 22, pp. 212-222, 2002.

[10] R. A. DeCarlo, et al., "Variable structure control of nonlinear multivariable systems: a tutorial," Proceedings of the IEEE, vol. 76, pp. 212-232, 2002.

[11] K. D. Young, et al., "A control engineer's guide to sliding mode control," 2002, pp. 1-14.

[12] Samira Soltani \& Farzin Piltan, "Design Artificial Nonlinear Controller Based on Computed Torque like Controller with Tunable Gain", World Applied Science Journal (WASJ), 14 (9): 1306-1312, 2011.

[13] Farzin Piltan, Mohammadali Dialame, Abbas Zare \& Ali Badri,"Design Novel Lookup Table Changed Auto Tuning FSMC:Applied to Robot Manipulator", International Journal of Engineering, 6 (1):25-41, 2012.

[14] Farzin Piltan, Mohammad Keshavarz, Ali Badri \& Arash Zargari,"Design Novel Nonlinear Controller Applied to RobotManipulator: Design New Feedback Linearization Fuzzy Controller with Minimum Rule Base Tuning Method", International Journal of Robotics and Automation,3 (1):1-12, 2012.

[15] Farzin Piltan, Iman Nazari, Sobhan Siamak, Payman Ferdosali,"Methodology of FPGA-Based Mathematical error-Based Tuning Sliding Mode Controller", International Journal of Control and Automation, 5(1), 89118, 2012.

[16] Farzin Piltan, Bamdad Boroomand, Arman Jahed \& Hossein Rezaie, "Methodology of Mathematical ErrorBased Tuning Sliding Mode Controller", International Journal of Engineering, 6 (2):96-117, 2012.

[17] Farzin Piltan, Sara Emamzadeh, Zahra Hivand, Fatemeh Shahriyari \& Mina Mirazaei, "PUMA-560 Robot Manipulator Position Sliding Mode Control Methods Using MATLAB/SIMULINK and Their Integration into Graduate/Undergraduate Nonlinear Control, Robotics and MATLAB Courses", International Journal of Robotics and Automation, 3(3):106-150, 2012.

[18] Farzin Piltan, Ali Hosainpour, Ebrahim Mazlomian, Mohammad Shamsodini, Mohammad H. Yarmahmoudi, "Online Tuning Chattering Free Sliding Mode Fuzzy Control Design: Lyapunov Approach", International Journal of Robotics and Automation, 3(3):77-105, 2012.

[19] Farzin Piltan, Mina Mirzaei, Forouzan Shahriari, Iman Nazari, Sara Emamzadeh, "Design Baseline Computed Torque Controller", International Journal of Engineering, 6(3): 129-141, 2012.

[20] Farzin Piltan, Mohammad H. Yarmahmoudi, Mohammad Shamsodini, Ebrahim Mazlomian, Ali Hosainpour, "PUMA-560 Robot Manipulator Position Computed Torque Control Methods Using MATLAB/SIMULINK and Their Integration into Graduate Nonlinear Control and MATLAB Courses", International Journal of Robotics and Automation, 3(3): 167-191, 2012.
[21] Farzin Piltan, Hossein Rezaie, Bamdad Boroomand, Arman Jahed, "Design Robust Backstepping on-line Tuning Feedback Linearization Control Applied to IC Engine", International Journal of Advance Science and Technology, 11:40-22, 2012.

[22] Farzin Piltan, Mohammad R. Rashidian, Mohammad Shamsodini and Sadeq Allahdadi, Effect of Rule Base on the Fuzzy-Based Tuning Fuzzy Sliding Mode Controller: Applied to 2nd Order Nonlinear System", International Journal of Advanced Science and Technology, 46:39-70, 2012.

[23] Farzin Piltan, Arman Jahed, Hossein Rezaie and Bamdad Boroomand, "Methodology of Robust Linear On-line High Speed Tuning for Stable Sliding Mode Controller: Applied to Nonlinear System", International Journal of Control and Automation, 5(3): 217-236, 2012.

[24] Farzin Piltan, Bamdad Boroomand, Arman Jahed and Hossein Rezaie, "Performance-Based Adaptive Gradient Descent Optimal Coefficient Fuzzy Sliding Mode Methodology", International Journal of Intelligent Systems and Applications, , vol.4, no.11, pp.40-52, 2012.

[25] Farzin Piltan, Mehdi Akbari, Mojdeh Piran , Mansour Bazregar, "Design Model Free Switching Gain Scheduling Baseline Controller with Application to Automotive Engine", International Journal of Information Technology and Computer Science, vol.5, no.1, pp.6573, 2013.DOI: 10.5815/ijitcs.2013.01.07.

[26] Farzin Piltan, Mojdeh Piran , Mansour Bazregar, Mehdi Akbari, "Design High Impact Fuzzy Baseline Variable Structure Methodology to Artificial Adjust Fuel Ratio", International Journal of Intelligent Systems and Applications, vol.5, no.2, pp.59-70, 2013.DOI: 10.5815/ijisa.2013.02.0.

[27] Farzin Piltan, M. Bazregar, M. kamgari, M. Akbari and M Piran, "Adjust the Fuel Ratio by High Impact Chattering Free Sliding Methodology with Application to Automotive Engine", International Journal of Hybrid Information Technology, 6(1), 2013.

[28] Farzin Piltan, S. Zare , F. ShahryarZadeh, M. Mansoorzadeh, M. kamgari, "Supervised Optimization of Fuel Ratio in IC Engine Based on Design Baseline Computed Fuel Methodology", International Journal of Information Technology and Computer Science , vol.5, no.4, pp.76-84, 2013.DOI: 10.5815/ijitcs.2013.04.09

[29] Farzin Piltan, M. Mansoorzadeh, S. Zare, F.Shahryarzadeh, M. Akbari, "Artificial Tune of Fuel Ratio: Design a Novel SISO Fuzzy Backstepping Adaptive Variable Structure Control", International Journal of Electrical and Computer Engineering, 3(2), 2013.

[30] M. Bazregar, Farzin Piltan, A. Nabaee and M.M. Ebrahimi, "Parallel Soft Computing Control Optimization Algorithm for Uncertainty Dynamic Systems", International Journal of Advanced Science and Technology, 51, 2013.

[31] Farzin Piltan, M.H. Yarmahmoudi, M. Mirzaei, S. Emamzadeh, Z. Hivand, "Design Novel Fuzzy Robust Feedback Linearization Control with Application to Robot Manipulator", International Journal of Intelligent Systems and Applications, vol.5, no.5, pp.1-10, 2013.DOI: 10.5815/ijisa.2013.05.01.

[32] Sh. Tayebi Haghighi, S. Soltani, Farzin Piltan, M. kamgari, S. Zare, "Evaluation Performance of IC Engine: Linear Tunable Gain Computed Torque Controller Vs. Sliding 
Mode Controller", International Journal of Intelligent Systems and Applications, vol.5, no.6, pp.78-88, 2013.DOI: 10.5815/ijisa.2013.06.10.

[33] Amin Jalali, Farzin Piltan, M. Keshtgar, M. Jalali, "Colonial Competitive Optimization Sliding Mode Controller with Application to Robot Manipulator", International Journal of Intelligent Systems and Applications, vol.5, no.7, pp.50-56, 2013. DOI: 10.5815/ijisa.2013.07.07.

[34] Salehi, Farzin Piltan, M. Mousavi, A. Khajeh, M. R. Rashidian, "Intelligent Robust Feed-forward Fuzzy Feedback Linearization Estimation of PID Control with Application to Continuum Robot", International Journal of Information Engineering and Electronic Business, vol.5, no.1, pp.1-16, 2013. DOI: 10.5815/ijieeb.2013.01.01.

[35] Farzin Piltan, M.J. Rafaati, F. Khazaeni, A. Hosainpour, S. Soltani, "A Design High Impact Lyapunov Fuzzy PDPlus-Gravity Controller with Application to Rigid Manipulator", International Journal of Information Engineering and Electronic Business, vol.5, no.1, pp.1725, 2013. DOI: 10.5815/ijieeb.2013.01.02.

[36] Amin Jalali, Farzin Piltan, A. Gavahian, M. Jalali, M. Adibi, "Model-Free Adaptive Fuzzy Sliding Mode Controller Optimized by Particle Swarm for Robot manipulator", International Journal of Information Engineering and Electronic Business, vol.5, no.1, pp.6878, 2013. DOI: 10.5815/ijieeb.2013.01.08.

[37] Farzin Piltan, F. ShahryarZadeh ,M. Mansoorzadeh ,M. kamgari, S. Zare, "Robust Fuzzy PD Method with Parallel Computed Fuel Ratio Estimation Applied to Automotive Engine", International Journal of Intelligent Systems and Applications, vol.5, no.8, pp.83-92, 2013. DOI: 10.5815/ijisa.2013.08.10.

[38] Farzin Piltan, A. Nabaee, M.M. Ebrahimi, M. Bazregar, "Design Robust Fuzzy Sliding Mode Control Technique for Robot Manipulator Systems with Modeling Uncertainties", International Journal of Information Technology and Computer Science, vol.5, no.8, pp.123135, 2013. DOI: 10.5815/ijitcs.2013.08.12.

[39] Farzin Piltan, M. Mansoorzadeh, M. Akbari, S. Zare, F. ShahryarZadeh "Management of Environmental Pollution by Intelligent Control of Fuel in an Internal Combustion Engine“ Global Journal of Biodiversity Science And Management, 3(1), 2013.

[40] M. M. Ebrahimit Farzin Piltan, M. Bazregar and A.R. Nabaee, "Intelligent Robust Fuzzy-Parallel Optimization Control of a Continuum Robot Manipulator", International Journal of Control and Automation, 6(3), 2013.

[41] O.R. Sadrnia, Farzin Piltan, M. Jafari, M. Eram and M. Shamsodini, "Design PID Estimator Fuzzy plus Backstepping to Control of Uncertain Continuum Robot", International Journal of Hybrid Information Technology, 6(4), 2013.

[42] AminJalali, Farzin Piltan, H. Hashemzadeh, A. Hasiri, M.R Hashemzadeh, "Design Novel Soft Computing Backstepping Controller with Application to Nonlinear Dynamic Uncertain System", International Journal of Intelligent Systems and Applications, vol.5, no.10, pp.93-105, 2013. DOI: 10.5815/ijisa.2013.10.12.

[43] M. Moosavi, M. Eram, A. Khajeh, O. Mahmoudi and Farzin Piltan, "Design New Artificial Intelligence Base Modified PID Hybrid Controller for Highly Nonlinear
System", International Journal of Advanced Science and Technology, 57, 2013.

[44] S. Zahmatkesh, Farzin Piltan, K. Heidari, M. Shamsodini, S. Heidari, "Artificial Error Tuning Based on Design a Novel SISO Fuzzy Backstepping Adaptive Variable Structure Control" International Journal of Intelligent Systems and Applications, vol.5, no.11, pp.34-46, 2013. DOI: 10.5815/ijisa.2013.11.04.

[45] S. Heidari, Farzin Piltan, M. Shamsodini, K. Heidari and S. Zahmatkesh, "Design New Nonlinear Controller with Parallel Fuzzy Inference System Compensator to Control of Continuum Robot Manipulator",International Journal of Control and Automation, 6(4), 2013.

[46] FarzinPiltan, M. Kamgari, S. Zare, F. ShahryarZadeh, M. Mansoorzadeh, "Design Novel Model Reference Artificial Intelligence Based Methodology to Optimized Fuel Ratio in IC Engine", International Journal of Information Engineering and Electronic Business, vol.5, no.2, pp.4451, 2013. DOI: 10.5815/ijieeb.2013.02.07.

[47] Farzin Piltan, Mehdi Eram, Mohammad Taghavi, Omid Reza Sadrnia, Mahdi Jafari,"Nonlinear Fuzzy Model-base Technique to Compensate Highly Nonlinear Continuum Robot Manipulator", IJISA, vol.5, no.12, pp.135-148, 2013. DOI: 10.5815/ijisa.2013.12.12.

[48] Amin Jalali, Farzin Piltan, Mohammadreza Hashemzadeh, Fatemeh BibakVaravi, Hossein Hashemzadeh,"Design Parallel Linear PD Compensation by Fuzzy Sliding Compensator for Continuum Robot", IJITCS, vol.5, no.12, pp.97-112, 2013. DOI: $10.5815 /$ ijitcs.2013.12.12.

[49] Farzin Piltan, A. Hosainpour, S. Emamzadeh, I. Nazari, M Mirzaie, "Design Sliding Mode Controller of with Parallel Fuzzy Inference System Compensator to Control of Robot Manipulator", International Journal of Robotics and Automation, Vol. 2, No. 4, December 2013, pp. 149 162.

[50] Farzin Piltan, Mahdi Jafari, Mehdi Eram, Omid Mahmoudi, Omid Reza Sadrnia, "Design Artificial Intelligence-Based Switching PD plus Gravity for Highly Nonlinear Second Order System", International Journal of Engineering and Manufacturing, vol.3, no.1, pp.38-57, 2013.DOI: 10.5815/ijem.2013.01.04.

[51] Farzin Piltan, Sara Emamzadeh, Sara Heidari, Samaneh Zahmatkesh, Kamran Heidari, "Design Artificial Intelligent Parallel Feedback Linearization of PID Control with Application to Continuum Robot", International Journal of Engineering and Manufacturing, vol.3, no.2, pp.51-72, 2013.DOI: 10.5815/ijem.2013.02.04.

[52] Mohammad Mahdi Ebrahimi, Farzin Piltan, Mansour Bazregar, AliReza Nabaee,"Artificial Chattering Free online Modified Sliding Mode Algorithm: Applied in Continuum Robot Manipulator", International Journal of Information Engineering and Electronic Business, vol.5, no.5, pp.57-69, 2013. DOI: 10.5815/ijieeb.2013.05.08.

[53] Arman Jahed, Farzin Piltan, Hossein Rezaie, Bamdad Boroomand, "Design Computed Torque Controller with Parallel Fuzzy Inference System Compensator to Control of Robot Manipulator", International Journal of Information Engineering and Electronic Business, vol.5, no.3, pp.66-77, 2013. DOI: 10.5815/ijieeb.2013.03.08.

[54] Mohammad Shamsodini, Farzin Piltan, Mahdi Jafari, Omid reza Sadrnia, Omid Mahmoudi,"Design Modified Fuzzy Hybrid Technique: Tuning By GDO", IJMECS, 
vol.5, no.8, pp.58-72, 2013.DOI: 10.5815/ijmecs.2013.08.07.

[55] Mahdi Mirshekaran, Farzin Piltan,Zahra Esmaeili, Tannaz Khajeaian, Meysam Kazeminasab,"Design Sliding Mode Modified Fuzzy Linear Controller with Application to Flexible Robot Manipulator", IJMECS, vol.5, no.10, pp.53-63, 2013.DOI: 10.5815/ijmecs.2013.10.07.

[56] Meysam Kazeminasab, Farzin Piltan, Zahra Esmaeili, Mahdi Mirshekaran, Alireza Salehi ,"Design Parallel Fuzzy Partly Inverse Dynamic Method plus Gravity Control for Highly Nonlinear Continuum Robot", IJISA, vol.6, no.1, pp.112-123, 2014. DOI: 10.5815/ijisa.2014.01.12.

[57] Mansour Bazregar, Farzin Piltan, Mehdi Akbari, Mojdeh Piran,"Management of Automotive Engine Based on Stable Fuzzy Technique with Parallel Sliding Mode Optimization", IJITCS, vol.6, no.1, pp.101-107, 2014. DOI: $10.5815 /$ ijitcs.2014.01.12.

[58] Mojdeh Piran, Farzin Piltan, Mehdi Akbari, Mansour Bazregar," Quality Model and Artificial Intelligence Base Fuel Ratio Management with Applications to Automotive Engine", IJISA, vol.6, no.2, pp.76-87, 2014. DOI: 10.5815/ijisa.2014.02.10.

[59] Ali Shahcheraghi, Farzin Piltan, Masoud Mokhtar, Omid Avatefipour, Alireza Khalilian," Design a Novel SISO Off-line Tuning of Modified PID Fuzzy Sliding Mode Controller", IJITCS, vol.6, no.2, pp.72-83, 2014. DOI: 10.5815/ijitcs.2014.02.10.

[60] Kamran Heidari, Farzin Piltan, Samaneh Zahmatkesh, Sara Heidari, Mahdi Jafari," Design High Efficiency Intelligent Robust Backstepping Controller ", IJIEEB, vol.5, no.6, pp.22-32, 2013. DOI: 10.5815/ijieeb.2013.06.03.

[61] Zahra Esmaieli, Farzin Piltan, Meysam Kazeminasab, Ali Reza Salehi, Mahdi Mirshekaran,"Design Intelligent Robust Back stepping Controller", IJMECS, vol.6, no.1, pp.53-64, 2014.DOI: 10.5815/ijmecs.2014.01.06.

[62] Omid Avatefipour, Farzin Piltan, Mahmoud Reza Safaei Nasrabad, Ghasem Sahamijoo, Alireza Khalilian,"Design New Robust Self Tuning Fuzzy Backstopping Methodology", IJIEEB, vol.6, no.1, pp.49-61, 2014. DOI: 10.5815/ijieeb.2014.01.06.

[63] Alireza Siahbazi, Ali Barzegar, Mahmood Vosoogh, Abdol Majid Mirshekaran, Samira Soltani,"Design Modified Sliding Mode Controller with Parallel Fuzzy Inference System Compensator to Control of Spherical Motor", IJISA, vol.6, no.3, pp.12-25, 2014. DOI: 10.5815/ijisa.2014.03.02.

[64] Narges Gholami Mozafari, Farzin Piltan, Mohammad Shamsodini, Azita Yazdanpanah, Ali Roshanzamir,"On Line Tuning Premise and Consequence FIS Based on Lyaponuv Theory with Application to Continuum Robot", IJISA, vol.6, no.3, pp.96-110, 2014. DOI: 10.5815/ijisa.2014.03.10.

[65] Mansour Bazregar, Farzin Piltan, AliReza Nabaee, MohammadMahdi Ebrahimi,"Design Modified Fuzzy PD Gravity Controller with Application to Continuum Robot", IJITCS, vol.6, no.3, pp.82-94, 2014. DOI: 10.5815/ijitcs.2014.03.10.

[66] Arzhang Khajeh, Farzin Piltan, Mohammad Reza Rashidian, Afsaneh Salehi, Ehsan pouladi ,"Design New Intelligent PID like Fuzzy Backstepping Controller ",
IJMECS, vol.6, no.2, pp.15-26, 2014.DOI: 10.5815/ijmecs.2014.02.03.

[67] Alireza Salehi, Farzin Piltan, Mahdi Mirshekaran, Meysam Kazeminasab, Zahra Esmaeili,"Comparative Study between Two Important Nonlinear Methodologies for Continuum Robot Manipulator Control", IJITCS, vol.6, no.4, pp.66-80, 2014. DOI: 10.5815/ijitcs.2014.04.08.

[68] Iman Nazari, Ali Hosainpour, Farzin Piltan, Sara Emamzadeh, Mina Mirzaie,"Design Sliding Mode Controller with Parallel Fuzzy Inference System Compensator to Control of Robot Manipulator", IJISA, vol.6, no.4, pp.63-75, 2014. DOI: 10.5815/ijisa.2014.04.07.

[69] Mojtaba Yaghoot, Farzin Piltan, Meysam Esmaeili, Mohammad Ali Tayebi, Mahsa Piltan,"Design Intelligent Robust Model-base Sliding Guidance Controller for Spherical Motor", IJMECS, vol.6, no.3, pp.61-72, 2014.DOI: 10.5815/ijmecs.2014.03.08.

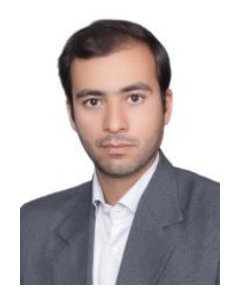

Ali Roshanzamir is currently working as a co researcher in Control and Robotic Lab at the institute of advance science and technology, IRAN SSP research and development Center. His current research interests are in the area of nonlinear control, artificial control system and robotics.

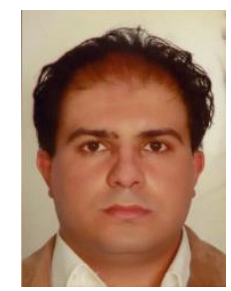

Farzin Piltan was born on 1975, Shiraz, Iran. In 2004 he is jointed the research and development company, SSP Co, Shiraz, Iran. In addition to 7 textbooks, Farzin Piltan is the main author of more than 100 scientific papers in refereed journals. He is editorial review board member for 'international journal of control and automation (IJCA), Australia, ISSN: 2005-4297; 'International Journal of Intelligent System and Applications (IJISA)', Hong Kong, ISSN: 2074-9058; 'IAES international journal of robotics and automation, Malaysia, ISSN: 2089-4856; 'International Journal of Reconfigurable and Embedded Systems', Malaysia, ISSN: 2089-4864. His current research interests are nonlinear control, artificial control system and applied to FPGA, robotics and artificial nonlinear control and IC engine modeling and control.

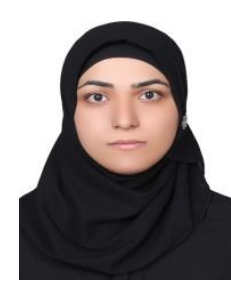

Narges Gholami mozafari is currently working as a co researcher in Control and Robotic Lab at the institute of advance science and technology, IRAN SSP research and development Center. Her current research interests are in the area of nonlinear control, artificial control system and robotics.

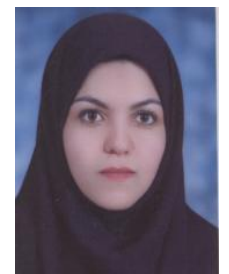

Azita Yazdanpanah is currently working as a co researcher in Control and Robotic Lab at the institute of advance science and technology, IRAN SSP research and development Center. She is a Master in field of Information Technology from Payamenoor University, IRAN. Her current research interests are in the area of nonlinear control, artificial control system and robotics. 


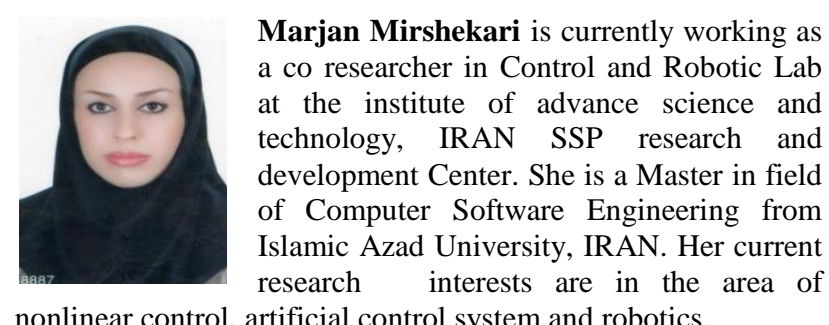
nonlinear control, artificial control system and robotics.

How to cite this paper: Ali Roshanzamir, Farzin Piltan, Narges Gholami mozafari, Azita Yazdanpanah, Marjan Mirshekari,"Design Intelligent Model base Online Tuning Methodology for Nonlinear System", IJMECS, vol.6, no.4, pp.46-56, 2014.DOI: 10.5815/ijmecs.2014.04.07 